\title{
Interaction between the VaR of cash flow and the interest rate using the ALM
}

\author{
El Hachloufi Mostafa ${ }^{1}$, Ezouine Driss ${ }^{2}$ and El Haddad Mohammed ${ }^{3}$
}

\begin{abstract}
In this paper, we propose an approach to study the impact of the interest rate on the risk of variation in cash flows measured by the value at risk (VaR) using stochastic processes and ALM technics. This approach provides a decision-making tool for manage asset, liability funds to bankers insurers and all companies operating in the financial sector.
\end{abstract}

Mathematics Subject Classification: 97K60

Keywords: Interest rates; VaR; cash flow; ALM Technics; Stochastic Processes

${ }^{1}$ Department of Management-Faculty of Juridical, Economical and Social Sciences University of Mohamed V, Rabat, Morocco E-mail: elhachloufi@yahoo.fr.

${ }^{2}$ Department of Management-Faculty of Juridical, Economical and Social Sciences University of Mohamed V, Rabat, Morocco. E-mail:ezouinedriss@gmail.com

${ }^{3}$ Department of Management-Faculty of Juridical, Economical and Social Sciences University of Mohamed V, Rabat, Morocco. E-mail: mo.haddad@hotmail.com

Article Info: Received : August 16, 2017. Revised : September 19, 2017.

Published online : January 5, 2018. 


\section{Introduction}

ALM is one of the main tools used to help solve rate variation problems in financial institutions such as banks and insurance companies. He plays a very important role in managing the various activities of the financial institute.

Appropriate liquidity and balance sheet management are a key factor in ensuring the activity of financial institutions and are a tool for managers to make decisions about risk management with variations in the interest rate.

The activities of companies, whether banks, insurance companies or for-profit corporations, generate cash flows affecting the balance sheet as assets or liabilities. This financial flow and its risk are influenced by the variation in the interest rate. In the case of a positive or negative variation, it will have an impact on the assets, liabilities or both at the same time.

The objective of this paper is to study this influence by treating the impact of the change in the interest rate on the risk of this flow.

\section{Financial flows}

The financial flow $\left(F_{i} / i=1, \ldots, n\right)$ of a company $E$ is the ensemble of $n$ amounts received or paid by it at different times $\left(t_{i} / i=1, \ldots, n\right)$ in future. In other words:

$$
\left\{\left(F_{i}, t_{i}\right) / i=1, \ldots, n\right\},
$$

where:

$F_{i}$ is the amount of the it ${ }^{\mathrm{h}}$ movement of the financial flow.

$t_{i}$ is the maturity of the it ${ }^{\mathrm{h}}$ movement of the financial flow. 


\section{Interest rate}

The interest rate is defined as the economic remuneration of time. This is the amount a borrower is willing to pay to his lender in addition to the capital, and it is based on the credit risk of that borrower.

The evolution of the interest rate can be modeled by several stochastic processes whose Vasicek process or model is the most popular. This stochastic process is called the process of return to the mean.

The Vasicek model assumes that the current short-term interest rate is known, while the future values of this rate follow the following equation:

$$
d r_{t}=\eta\left(\bar{r}-r_{t}\right) d t+\sigma d z_{t}
$$

Where :

$\eta:$ is the rate of return of the interest rate to the average.

$\bar{r}:$ is the average interest rate.

$\sigma:$ is the volatility of the interest rate which is assumed to be independentof $r_{t}$ $z_{t}$ : is a Brownian movement such as $d z_{t}=\varepsilon_{t} \sqrt{d t}$ avec $\varepsilon_{t} \sim N(0,1)$

\section{Elements of Asset and Liability Management (ALM)}

Asset-liability management aims at controlling financial risks and the consistency of the various balance sheet items over a time horizon. The objective of the ALM is to contribute to the achievement of the overall objectives of the bank and the insurance company's top management while taking the regulatory constraints into account in order to adopt an adequate financing policy. 


\section{Value at Risk (VaR)}

The VaR is a measure of risk most widely used in financial markets to quantify the maximum loss on a portfolio for a given horizon and confidence level. It depends on three elements:

i. The distribution of the portfolio's profits and losses for the holding period.

ii. The level of confidence.

iii. The holding period of the asset.

Analytically, the VaR with time horizon $t$ and the threshold probability $\alpha$ the number $\operatorname{VaR}(t, \alpha)$ such as:

$$
\mathrm{P}[\Delta R \leq \operatorname{VaR}(t, \alpha)]=\alpha
$$

where :

$t$ : Horizon associated with VaR which is: 1 day or more than one day.

$\alpha$ : The probability level is typically $95 \%, 98 \%$ or $99 \%$.

\section{The VaR of financial flow and the interest rate}

The financial flow $F_{i}, i=1, \ldots, n$ from a company $E$ is a set of $n$ amounts received or paid by it at different times $t_{i}, i=1, \ldots, n$ to the future whose interest rate corresponds to the $t_{i}$ is $r_{t_{i}}$. Interest rates $r_{t_{i}}, i=1, \ldots, n$ are assumed to be independent.

The present value of this financial flow is given by:

$V_{r}=\sum_{i=1}^{n} F_{i} r_{t_{i}}=F_{1} r_{t_{1}}+F_{2} r_{t_{2}}+\ldots+F_{n} r_{t_{n}}$

Consider two future flows: assets $\mathrm{A}$ and liabilities $\mathrm{P}$ given by :

$$
\left.A=\left\{\left(A_{i}, r_{t_{i}}\right), \quad \mathrm{i}=1, \ldots, n\right\}\right), \quad \mathrm{P}=\left\{\left(P_{i}, r_{t_{i}}\right), \quad \mathrm{i}=1, \ldots, n\right\}
$$


The surplus relative to the couple of flow $\{A, P\}$ in relation to the interest rate $r_{t_{i}}$, $\mathrm{i}=1, \ldots, n$, noted $S_{r_{t}}$, is given by:

$S_{r_{t}}=\sum_{i=1}^{n}\left(A_{i}-P_{i}\right) \times r_{t_{i}}$

or

$$
S_{r_{t}}=\sum_{i=1}^{n} A P_{i} \times r_{t_{i}}=\sum_{i=1}^{n} F_{i} \times r_{t_{i}} \quad \text { where } \quad F_{i}=A P_{i}=\left(A_{i}-P_{i}\right)
$$

Assuming that the interest rate follows a Vasicek process, i.e :

$$
d r_{t}=\eta\left(\bar{r}-r_{t}\right) d t+\sigma d z_{t}
$$

Thus, we can develop this model which is used to describe the interest rate as follows:

$$
d\left(e^{\eta t} r_{t}\right)=e^{\eta t} d r_{t}+r_{t} \eta e^{\eta t} \Rightarrow e^{\eta t} d r_{t}=d\left(e^{\eta t} r_{t}\right)-r_{t} \eta e^{\eta t}
$$

In other,

$$
d r_{t}=\eta\left(\bar{r}-r_{t}\right) d t+\sigma d z_{t} \Rightarrow e^{\eta t} d r_{t}=e^{\eta t} \eta\left(\bar{r}-r_{t}\right) d t+e^{\eta t} \sigma d z_{t}
$$

Then we get:

$$
d\left(e^{\eta t} r_{t}\right)=\eta \bar{r} e^{\eta t} d t+e^{\eta t} \sigma d z_{t} \Rightarrow r_{t}=r_{0} e^{-\eta t}+\int_{0}^{t} \eta e^{-\eta(t-s)} \overline{r d s}+\sigma \int_{0}^{t} e^{-\eta(t-s)} d z_{s}
$$

So the interest rate $r_{t}$ can be expressed as follows:

$$
r_{t}=\bar{r}+\left(r_{0}-\bar{r}\right) e^{-\eta t}+\sigma \int_{0}^{t} e^{-\eta(t-s)} d z_{s}
$$

Knowing that $z_{t}$ is a process such as $d z_{t}=\varepsilon_{t} \sqrt{d t}$ with $\varepsilon_{t} \rightarrow N(0,1)$, so $d z_{t}$ follows the normal distribution and the variable $\left(\sigma \int_{0}^{t} \eta e^{-\eta(t-s)} d z_{s}\right)$ also follows the normal distribution.

The term $\bar{r}+\left(r_{0}-\bar{r}\right) e^{-\eta t}$ is not a random term then $r_{t} \mid r_{0}$ is a random variable that follows the normal distribution.

Using Iso isometry we find that:

$E\left[\left(\sigma \int_{0}^{t} \eta e^{-\eta(t-s)} d z_{s}\right)\right]=0$ 
and

$$
E\left[\left(\sigma \int_{0}^{t} \eta e^{-\eta(t-s)} d z_{s}\right)^{2}\right]=\int_{0}^{t}\left(\sigma e^{-\eta(t-s)}\right) d s=\frac{\sigma^{2}}{2 \eta}\left(1-e^{-2 \eta t}\right)
$$

Then the mean and the variance are respectively:

$E\left(r_{t} \mid r_{0}\right)=\bar{r}+\left(r_{0}-\bar{r}\right) e^{-\eta t}$

$V\left(r_{t} \mid r_{0}\right)=\frac{\sigma^{2}}{2 \eta}\left(1-e^{-2 \eta t}\right)$

So the random variable $r_{t} \mid r_{0}$ follows the normal distribution of mean and variance respectively $\bar{r}+\left(r_{0}-\bar{r}\right) e^{-\eta t}$ et $\frac{\sigma^{2}}{2 \eta}\left(1-e^{-2 \eta t}\right)$, i.e :

$$
r_{t} \rightarrow N\left(\bar{r}+\left(r_{0}-\bar{r}\right) e^{-\eta t}, \sigma \sqrt{\frac{1}{2 \eta}\left(1-e^{-2 \eta t}\right)}\right)
$$

Knowing that:

$$
V_{r_{t}}=\sum_{i=1}^{n} F_{i} r_{t_{i}}=F_{1} r_{t_{1}}+F_{2} r_{t_{2}}+\ldots+F_{n} r_{t_{n}} \text { so } d V_{r_{t}}=\sum_{i=1}^{n} F_{i} d r_{t_{i}}
$$

and

$$
\begin{aligned}
& d r_{t}=\eta\left(\bar{r}-r_{t}\right) d t+\sigma d z_{t} \text { so } d V_{r_{t}}=\sum_{i=1}^{n} F_{i} d r_{t_{i}}=\sum_{i=1}^{n} F_{i}\left[\eta\left(\bar{r}-r_{t_{i}}\right) d t_{i}+\sigma d z_{t_{i}}\right] \\
& \Rightarrow d V_{r_{t}}=\sum_{i=1}^{n} F_{i} \eta\left(\bar{r}-r_{t_{i}}\right) d t_{i}+F_{i} \sigma d z_{t_{i}} \Rightarrow \Delta V_{r_{t}}=\sum_{i=1}^{n} F_{i} \eta\left(\bar{r}-r_{t_{i}}\right) \Delta t_{i}+F_{i} \sigma \sqrt{\Delta t_{i}} \varepsilon_{t_{i}}
\end{aligned}
$$

So $E\left(\Delta V_{r_{t}}\right)=\sum_{i=1}^{n} F_{i} \eta\left(\bar{r}-r_{t_{i}}\right) \Delta t_{i} \quad$ and $\quad V\left(\Delta V_{r_{t}}\right)=\sum_{i=1}^{n}\left(\sigma F_{i}\right)^{2} \Delta t_{i}$

Let $\alpha_{t}=\sum_{i=1}^{n} F_{i} \eta\left(\bar{r}-r_{t_{i}}\right) \Delta t_{i} \quad$ and $\beta_{t}=\sum_{i=1}^{n}\left(\sigma F_{i}\right)^{2} \Delta t_{i}$ then $\Delta V_{r_{t}} \rightarrow N\left(\alpha_{t}, \sqrt{\beta_{t}}\right)$

The calculation of the $\mathrm{VaR}$ at $\alpha$ is given by the following equation:

$P\left(\Delta V_{r_{t}} \leq \operatorname{VaR}_{\alpha}\right)=\alpha$

Knowing that $\Delta V_{r_{t}} \rightarrow N\left(\alpha_{t}, \sqrt{\beta_{t}}\right)$, therefore 


$$
P\left(\frac{\Delta V_{r_{t}}-\alpha_{t}}{\sqrt{\beta_{t}}} \leq \frac{\operatorname{VaR}_{\alpha}-\alpha_{t}}{\sqrt{\beta_{t}}}\right)=\alpha \Rightarrow \frac{\operatorname{VaR}_{\alpha}-\alpha_{t}}{\sqrt{\beta_{t}}}=\tau_{\alpha}
$$

Thus

$$
V a R_{\alpha}=\sum_{i=1}^{n} \eta F_{i}\left(\bar{r}-r_{t_{i}}\right) \Delta t_{i}+\tau_{\alpha} \sigma^{2} \sum_{i=1}^{n} F_{i}^{2} \Delta t_{i}
$$

\section{Numerical application}

In this section we will present a numerical application of $\mathrm{VaR}$ calculation expressed by the equation above using the financial flows of the company WAFA ASSURANCE below from the period from 2006 to 2016.

Table 1: Financial flows of the company WAFA ASSURANCE

\begin{tabular}{|l|l|l|l|l|l|l|}
\hline & F1 & F2 & F3 & F4 & F5 & F6 \\
\hline 2006 & 1000457232,86 & 43345882,71 & 751712237,37 & 358385435,43 & 535546854,47 & 39977696,99 \\
\hline 2007 & 1129148572,00 & 35608429,29 & 758245958,15 & 401714775,10 & 682949812,32 & 52330487,69 \\
\hline 2008 & 1188991849,55 & 37615635,64 & 768423035,45 & 423851648,39 & 587056882,60 & 27961330,07 \\
\hline 2009 & 1396390661,85 & 39765498,38 & 901720102,38 & 474836763,03 & 1028061612,10 & 154267498,27 \\
\hline 2010 & 1850336661,33 & 101863920,31 & 1249534438,35 & 586405141,15 & 688553169,53 & 37307656,23 \\
\hline 2011 & 2114643387,73 & 82173954,20 & 1408920653,90 & 615208768,23 & 924609641,72 & 208008777,91 \\
\hline 2012 & 2271516541,81 & 56430276,03 & 1486121586,17 & 717982870,52 & 1017221090,00 & 404260566,07 \\
\hline 2013 & 2456622991,48 & 19749435,01 & 1562056658,19 & 764460236,87 & 714551385,43 & 68786404,06 \\
\hline 2014 & 2590396273,70 & 18016234,42 & 1678304389,51 & 804423121,95 & 615025258,10 & 101480107,05 \\
\hline 2015 & 2440076544,89 & 62456800,33 & 1543050391,84 & 801223719,04 & 703964022,72 & 202035529,43 \\
\hline 2016 & 2783651061,17 & 56620240,37 & 1833957307,21 & 932080831,33 & 919882144,88 & 33280484,51 \\
\hline
\end{tabular}

The table above is composed of inputs such as premiums and technical products of operations. In addition to, the outputs such as operating expenses and investment expenses. This inputs and outputs are:

$\mathrm{F} 1$ = premiums

F2 = Technical operating products 
F3 = Benefits and expenses

F4 $=$ Technical operating expenses

F5 = Investment income allocated to insurance operations.

F6 $=$ Charges of investments affected to insurance transactions

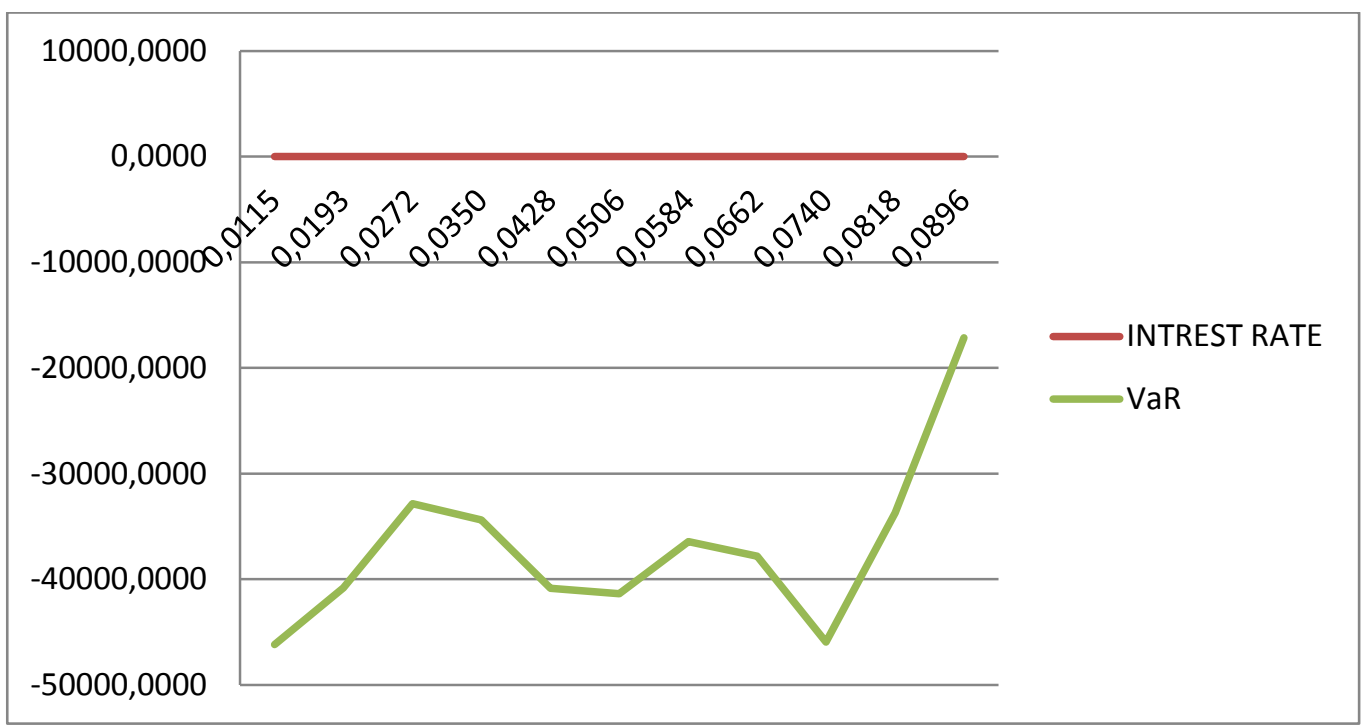

Figure 1: VaR depending on interest rates of company of LIFE-INSURANCE

The graphical representation of the VaR given by equation (4) illustrate by the Figure 1. This figure shows that there is an interaction between the $\mathrm{VaR}$ of financial flow and the interest rate. Indeed, we note that the $\mathrm{VaR}$ is impacted directly by the interest rate and it is positively correlated to the same rate.

\section{Conclusion}

In this paper, we have developed an approach based on a mathematical formula to study the impact of the interest rate on the risk of the financial flow 
using value at risk as a risk measure and ALM to express the variability of a company's financial flows.

This approach allows us to evaluate the risk of financial flows in relation to the variation in the interest rate which gives rise to a decision-making tool for the management of funds, whether at the level of the assets or the liabilities of the company.

\section{References}

[1] Philippe Jorion, Value At Risk The New Benchmark for Managing Financial Risk, Third Edition, 2007.

[2] Chang, H., Dynamic mean-variance portfolio selection with liability and stochastic interest rate. Econ. Model. 51, 172-182 (2015).

[3] Dan, R., and Stavros A., Z., Handbook of Asset Liability Management, volume 1, Br. Columbia, (2015), 1689-1699.

[4] M.A.H. Dempster, M. Germano, E.A. Medova and M. Villaverde, Global Asset Liability Management, 2002.

[5] Alexandre Adam, Handbook of Asset and Liability Management From Models to Optimal return strategies, 2007.

[6] Moorad Choudhry, Bank Asset and Liability Management Strategy, Trading, Analysis, published by John Wiley \& sons (Asia), Pte Ltd (2007).

[7] Umut Celiker, Volkan Kayacetin, Raman Kumar, Gokhan Sonaer, Cash Flow News, Discount Rate News and Momentum, Journal of Banking and Finance, (2016).

[8] Xiaoyu Wang, Dejun Xie, Jingjing Jiang, Xiaoxia Wu, Jia He, Valueat-Risk Estimation with Stochastic Interest Rate Models for Option-Bond Portfolios, Finance Research Letters, (2016).

[9] Ali Anari and James Kolari, Dynamics of Interest and Inflation Rates, Journal of Empirical Finance (2016). 
[10] Jörgen Blomvall, Measurement of interest rates using a convex optimization model, European Journal of Operational Research, (2017).

[11] Yonghui Zhang, Zhongtian Chen and Yong Li, Bayesian testing for short term interest rate models, Finance Research Letters, (2016).

[12] Xiaoyu Wang, Dejun Xie, Jingjing Jiang, Xiaoxia Wu and Jia He, ValueatRisk Estimation with Stochastic Interest Rate Models for Option-Bond Portfolios, Finance Research Letters, (2016). 